\title{
Large vessel vasculopathy in a patient with systemic lupus erythematosus: a case report
}

\author{
Daisuke Waki, Akira Onishi* ${ }^{*}$ and Akio Morinobu
}

\begin{abstract}
Background: Vasculopathy in systemic lupus erythematosus is a rare form of vascular involvement characterized by non-inflammatory vascular injury with the accumulation of immune complexes in the walls of the arteries, resulting in luminal narrowing. While previous reports have demonstrated vasculitis in the large vessels or vasculopathy in the small vessels, vasculopathy in large vessels has not yet been reported.

Case presentation: We present the case of a 43-year-old Japanese woman with peripheral large vessel vasculopathy associated with systemic lupus erythematosus. She presented a 7-year history of progressive headaches and intermittent claudication, although she had no atherosclerotic risk factors. Vascular ultrasonography and enhanced computed tomography showed multiple vascular stenoses and occlusion. The histological findings of her left temporal artery revealed narrowing of the lumen caused by intimal thickening without inflammatory cells and the deposition of immunoglobulin G, complement component 3, and fibrinogen in the wall of the intima. Beraprost and cilostazol improved arterial occlusion without immunosuppressive therapy.
\end{abstract}

Conclusions: Large vessel vasculopathy should be considered another potential cause of arterial stenoses and occlusion in patients with lupus when they have peripheral arterial disease despite having no atherosclerotic risk factors.

Keywords: Systemic lupus erythematosus, Vasculopathy, Vasculitis, Large vessel vasculopathy

\section{Background}

Vasculopathy in systemic lupus erythematosus (SLE) is a rare form of vascular involvement characterized by arterial stenosis or occlusion, with the accumulation of immunoglobulins and complement in the arterial intima and no inflammatory change [1]. Vasculopathy should be distinguished from vasculitis histopathologically, as vascular lesions in lupus kidney disease can be categorized as non-inflammatory vascular immune complex deposits (vasculopathy), inflammatory vasculitis, thrombotic microangiopathies, and degenerative disorders/arteriosclerosis [1]. While previous studies have reported vasculitis in large vessels or vasculopathy in small vessels of the kidney in SLE, large vessel vasculopathy has not been reported.

\footnotetext{
* Correspondence: aonishi@med.kobe-u.ac.jp

Department of Rheumatology and Clinical Immunology, Kobe University Graduate School of Medicine, 7-5-1 Kusunoki-cho, Chuo-ku, Kobe 650-0017, Japan
}

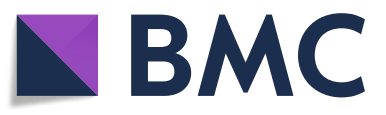

(c) The Author(s). 2019 Open Access This article is distributed under the terms of the Creative Commons Attribution 4.0 International License (http://creativecommons.org/licenses/by/4.0/), which permits unrestricted use, distribution, and reproduction in any medium, provided you give appropriate credit to the original author(s) and the source, provide a link to the Creative Commons license, and indicate if changes were made. The Creative Commons Public Domain Dedication waiver (http://creativecommons.org/publicdomain/zero/1.0/) applies to the data made available in this article, unless otherwise stated.
Here we present, to the best of our knowledge, the first case of peripheral large vessel vasculopathy associated with SLE. The possibility of large vessel vasculopathy should be considered in a patient with lupus when the patient has peripheral arterial disease, despite having no atherosclerotic risk factors.

\section{Case presentation}

A 43-year-old Japanese woman presented to our hospital with a 7-year history of progressive headaches and intermittent claudication. She was diagnosed as having SLE according to the 1997 American College of Rheumatology revised classification criteria (oral ulcers, discoid rashes, positive anti-nuclear antibody, leukopenia, and lymphopenia) [2] and histological findings of the skin (interface dermatitis and positive lupus band test) 11 years previously, all of which improved with low-dose prednisolone. She had no atherosclerotic risk factors such as cigarette smoking, dyslipidemia, diabetes mellitus, or hypertension. She drank alcohol only on social occasions 
and had no significant other past medical, social, environmental, obstetrical, gynecological, or employment history. Her mother had autoimmune hepatitis and died at the age of 60 of subarachnoid hemorrhage. On hospitalization, her temperature was $36.0{ }^{\circ} \mathrm{C}$, her blood pressure was $124 / 82 \mathrm{mmHg}$, and her pulse was 78 per minute, regular and of normal tension. A physical examination revealed the absence of pulsation in the bilateral posterior tibial arteries and the left dorsalis pedis artery. She had no adenopathy, aphthous ulcers, or rash. Her heart sounds were clear and regular without audible murmurs and her lungs were clear. Her abdomen was flat and soft, and bowel sounds were normal without murmurs. A neurological examination showed that her cranial nerves were intact, her muscle strength was normal, her deep tendon reflexes were symmetrical without Babinski sign, and no sensory abnormalities were noted. Laboratory data revealed mild leukopenia $(3300 / \mu \mathrm{L})$ and slightly elevated erythrocyte sedimentation rate $(24 \mathrm{~mm} /$ hour$)$. C-reactive protein level, complement level, and urine sediment were normal. Anti-double-stranded deoxyribonucleic acid (dsDNA), anti-Smith, anti-cardiolipin, anti-neutrophil cytoplasmic antibodies, and lupus anticoagulant were all negative. Vascular ultrasonography revealed occlusion of her bilateral posterior tibial arteries, bilateral peroneal arteries, and left anterior tibial artery with collateral circulation and wall thickening of her right radial artery. Luminal narrowing in her right temporal artery and concentric hypoechoic mural thickening (the halo sign) in her left temporal artery were detected, although no abnormalities in her carotid arteries were found (Fig. 1A).
Enhanced computed tomography showed vascular occlusion of bilateral lower limbs and her right ophthalmic artery (Fig. 1B, C). Enhanced magnetic resonance imaging and positron emission tomography revealed no inflammation in the wall of the large vessels. The histological findings of the left temporal artery revealed narrowing of the lumen caused by intimal thickening without inflammatory cells, and the deposition of immunoglobulin G (IgG), complement component 3 (C3), and fibrinogen in the wall of the intima (Fig. 2). Atherosclerotic changes, such as fibrous plaque, foam cells, or Monckeberg's calcification, were not found. Active or healed arteritis, including giant cells within the intima, fragmentation, loss of internal elastic lamina, or neovascularization of the media, was not detected.

We made a diagnosis of large vessel vasculopathy associated with SLE based on the histopathological findings. Vascular involvements were only observed in the peripheral large vessel according to the Chapel Hill Consensus Conference nomenclature system [3]. We initiated $120 \mu \mathrm{g} /$ day of beraprost sodium and $200 \mathrm{mg} /$ day of cilostazol therapy orally. At 6 months after discharge, re-examination by ultrasonography revealed recanalization in our patient's left posterior tibial artery.

\section{Discussion and conclusions}

To the best of our knowledge, this is the first report of peripheral large vessel vasculopathy associated with SLE and demonstrates two important points.

First, vasculopathy, as well as vasculitis, may occur in the large vessel. Although several reports showed large vessel involvements in SLE, all of them demonstrated

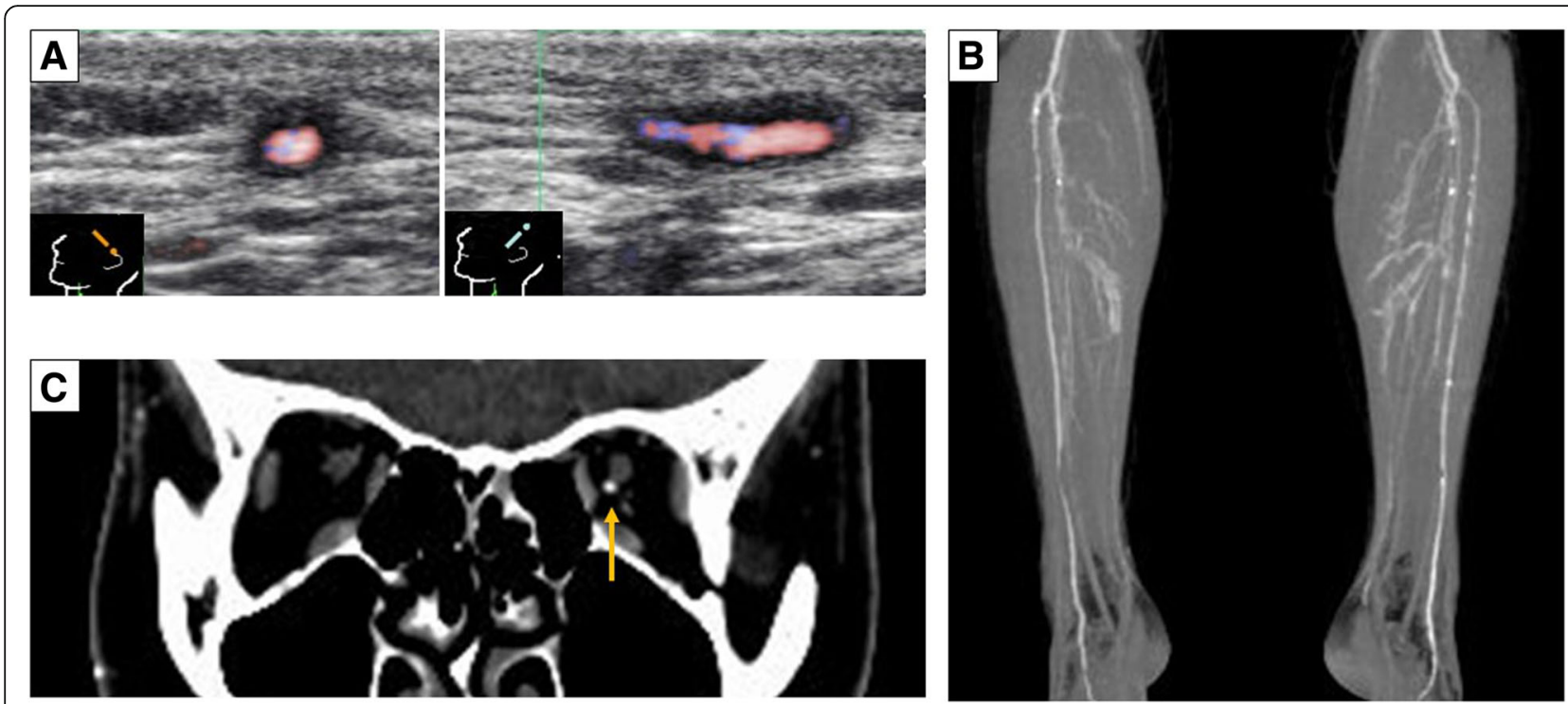

Fig. 1 Multiple vascular stenoses and occlusion. a Vascular ultrasonography revealed concentric hypoechoic mural thickening (the halo sign) in the left temporal artery. $\mathbf{b}$ Reconstruction image of an enhanced computed tomography scan showed bilateral occlusion of the posterior tibial arteries and the peroneal arteries. c Enhanced computed tomography showed occlusion of the right ophthalmic artery while the left ophthalmic artery was normally detected (yellow arrow) 

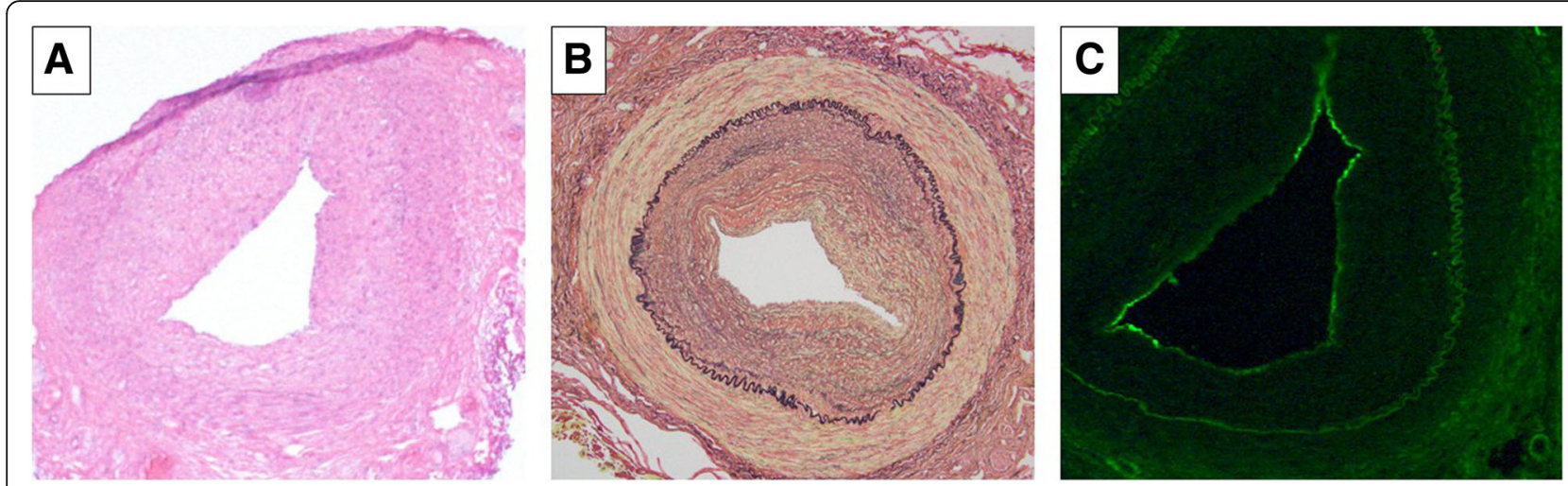

Fig. 2 Histological findings of the left temporal artery. a Hematoxylin and eosin staining revealed a lumen narrowed by intimal thickening, without inflammatory cells. There was no evidence of atherosclerotic findings (lipid accumulations and fibrous caps), Monckeberg's calcification, or active temporal arteritis. b Elastica-van Gieson staining did not show fragmentation and loss of elastic fibers in the internal elastic lamina. c The wall of the intima was stained with C3 and evaluated by immunofluorescence

vasculitis or thrombosis of large vessel [4-8]. Takagi et al. reported a case of SLE with non-dissecting aneurysm that was successfully resected, replaced with a tube graft, and proven to be active aortitis [6]. In this patient, focal calcification and atheroma were found within the thickened intima, which contained activated $\mathrm{T}$ and $\mathrm{B}$ lymphocytes in a perivascular lesion. However, some previous publications might include cases with large vessel vasculopathy especially when they were diagnosed only with angiography because vasculopathy is often confused with vasculitis. In contrast, the present case showed only a thickened intima with immunoglobulins and complement deposition, without any inflammatory lymphocyte infiltration or atherosclerotic change, which are typical features of vasculopathy.

Second, the present case had vasculopathy in the large vessel, not the small or medium vessel. Lupus vasculopathy is commonly found in the kidney. Pathological findings in renal lupus vasculopathy are mainly present in small vessels, such as the pre-glomerular arterioles and small arteries [1]. In addition, although cases of extra-renal vasculopathy in lupus were rarely reported, all were shown to involve the small vessels [9-11]. In contrast, the present case was demonstrated to have peripheral large vessel vasculopathy based on temporal artery biopsy.

Several limitations should be noted. First, a previous use of prednisolone might modulate pathological findings. Differential diagnoses of large vessel vasculopathy include atherosclerosis and healed vasculitis. Although accelerated atherosclerosis is a common complication in SLE [12], the pathological findings of the present case did not show atherosclerotic changes such as fatty streak or atheroma $[13,14]$. In addition, healed temporal arteritis was less likely to occur in this case as there were no neovascularizations of the media or loss of the internal elastic lamina [15]. Second, we could not speculate regarding the incidence or prevalence of vasculopathy based on the nature of the case reports. Some peripheral large vessel vasculopathy may, however, remain unrecognized among patients with SLE with peripheral arterial diseases. Thus, further studies are needed to determine the prevalence of vasculopathy among patients with SLE with peripheral arterial disease.

The present case was treated without immunosuppressive therapy. Although previous cases of lupus vasculopathy were mainly treated with immunosuppressive therapy because of coincidental active lupus involvement or its hypothesized mechanism, it has not been established whether conventional immunosuppressive agents are effective $[1,10]$. Sugimoto et al. reported a case of renal lupus vasculopathy without active glomerular lesions successfully treated without immunosuppressive therapy [16]. The patient, who had a previous medical history of central nervous system lupus, developed acute renal infarction and multiple arterial stenoses in the interlobular arteries. Because no active inflammatory changes were found during renal biopsy, they did not initiate immunosuppressive therapy, which resulted in the improvement of renal dysfunction. The present case also experienced improvement of arterial occlusion without immunosuppressive therapy. Further reports should be accumulated to determine whether immunosuppressive agents are needed to treat lupus vasculopathy without active inflammation.

In conclusion, peripheral large vessel vasculopathy may occur in patients with SLE. Physicians should consider the possibility of large vessel vasculopathy in a patient with lupus when the patient has peripheral arterial disease, despite having no atherosclerotic risk factors. 


\section{Abbreviation}

SLE: Systemic lupus erythematosus

\section{Acknowledgements}

Not applicable.

\section{Authors' contributions}

DW wrote the initial draft of this manuscript. AO wrote the initial draft of this manuscript, subsequent revisions, and is responsible for the oversight of the report and editing the manuscript. AM reviewed the manuscript and contributed to the discussion. All authors have read and approved the final manuscript.

\section{Funding}

The authors received no financial support for the research and/or authorship of this article.

\section{Availability of data and materials}

Because this is a case report of a single patient, there are no available raw data, this is to protect her privacy and respect confidentiality. The original reports, laboratory studies, imaging studies, and out-patient clinic records are retained as per normal procedure within the medical records of our institution.

\section{Ethics approval and consent to participate}

Ethical approval for publishing a case report is not needed from our institute (Kobe University Graduate School of Medicine).

\section{Consent for publication}

Written informed consent was obtained from the patient for publication of this case report and any accompanying images. A copy of the written consent is available for review by the Editor-in-Chief of this journal.

\section{Competing interests}

The authors declare that they have no competing interests.

Received: 19 March 2019 Accepted: 16 May 2019

Published online: 22 June 2019

\section{References}

1. Gonzalez-Suarez ML, Waheed AA, Andrews DM, Ascherman DP, Zeng X, Nayer A. Lupus vasculopathy: diagnostic, pathogenetic and therapeutic considerations. Lupus. 2014;23:421-7.

2. Hochberg MC. Updating the American College of Rheumatology revised criteria for the classification of systemic lupus erythematosus. Arthritis Rheum. 1997:40:1725.

3. Jennette JC, Falk RJ, Bacon PA, Basu N, Cid MC, Ferrario F, et al. 2012 revised international Chapel Hill consensus conference nomenclature of vasculitides. Arthritis Rheum. 2013;65:1-11.

4. Willett WF, Kahn MJ, Gerber MA. Lupus aortitis: a case report and review of the literature. J La State Med Soc. 1996;148:55-9.

5. Wang J, French SW, Chuang CC, McPhaul L. Pathologic quiz case: An unusual complication of systemic lupus erythematosus. Arch Pathol Lab Med. 2000;124:324-6.

6. Takagi H, Mori Y, Iwata H, Kimura M, Itokazu M, Shimokawa K, et al. Nondissecting aneurysm of the thoracic aorta with arteritis in systemic lupus erythematosus. J Vasc Surg. 2002;35:801-4.

7. Ferreiro JE, Pallares VA. Systemic lupus erythematosus with tibial arteritis and foot gangrene. J Fla Med Assoc. 1988:75:801-4.

8. Harmon SM, Oltmanns KL, Min KW. Large vessel occlusion with vasculitis in systemic lupus erythematosus. South Med J. 1991;84:1150-4.

9. Hughson MD, He Z, Henegar J, McMurray R. Alveolar hemorrhage and renal microangiopathy in systemic lupus erythematosus: immune complex small vascular injury with apoptosis. Arch Pathol Lab Med. 2001;125:475-83.

10. Sung JM, Hsu SC, Chen FF, Huang JJ. Systemic lupus erythematosus presented as non-inflammatory necrotizing vasculopathy-induced ischemic glomerulopathy and small vessels-related ischemic cardiomyopathy. Lupus. 2002:11:458-62

11. Nag TC, Wadhwa S. Vascular changes of retina and choroids in systemic lupus erythematosus: pathology and pathogenesis. Curr Neurovasc Res. 2006;:159-68
12. Roman MJ, Shanker BA, Davis A, Lockshin MD, Sammaritano L, Simantov R, et al. Prevalence and correlates of accelerated atherosclerosis in systemic lupus erythematosus. N Engl J Med. 2003;349:2399-406.

13. Virmani R, Kolodgie FD, Burke AP, Farb A, Schwartz SM. Lessons from sudden coronary death: a comprehensive morphological classification scheme for atherosclerotic lesions. Arterioscler Thromb Vasc Biol. 2000:20:1262-75.

14. Insull WJ. The pathology of atherosclerosis: plaque development and plaque responses to medical treatment. Am J Med. 2009;122:S3-14.

15. Lee YC, Padera RF, Noss EH, Fossel AH, Bienfang D, Liang MH, et al. Clinical course and management of a consecutive series of patients with "healed temporal arteritis". J Rheumatol. 2012;39:295-302.

16. Sugimoto T, Kanasaki K, Morita Y, Yokomaku Y, Narita M, Koyama T, et al. Lupus vasculopathy combined with renal infarction: Unusual manifestation of lupus nephritis. Intern Med. 2005:44:1185-90.

\section{Publisher's Note}

Springer Nature remains neutral with regard to jurisdictional claims in published maps and institutional affiliations.

Ready to submit your research? Choose BMC and benefit from:

- fast, convenient online submission

- thorough peer review by experienced researchers in your field

- rapid publication on acceptance

- support for research data, including large and complex data types

- gold Open Access which fosters wider collaboration and increased citations - maximum visibility for your research: over $100 \mathrm{M}$ website views per year

At BMC, research is always in progress.

Learn more biomedcentral.com/submissions 